\title{
ORGANIZATIONAL AND PROFESSIONAL FACTORS OF PERFECTIONISM IN SCIENTIFIC AND PEDAGOGICAL STAFF OF HIGHER SCHOOL
}

\author{
Tamara Grubi \\ Borys Grinchenko Kyiv University, Ukraine
}

\begin{abstract}
The attention to the study of perfectionism in high school in Ukraine can be explained with modernization and development of Ukrainian higher education, as an access to the European educational research environment. The interest to the perfectionism in scientific and pedagogical staff of high school can be explained by new requirements for professional activity and these factors demand from a teacher of higher school can be an achievement of new standards, obtaining successfully by focusing on avoiding failures. The study is conducted within the pedagogy field. In this article, the author identifies and analyzes the impact of socialdemographic factors (such as age, gender, place of residence), organizational and professional factors (such as job experience, academic degree, post, direction of teaching activity, number of students, level of famousness of higher school, level of social-psychological climate etc.). The four manifestations of perfectionism, which are:

- Absence of perfectionism - where normal and pathological perfectionism are represented at a low level.

- Perfectionism with negative orientation - consists of the respondents with pathological type of perfectionism.

- Ambivalent perfectionism - included the respondents in which the pathological and normal types of perfectionism are equally highly represented.

- Perfectionism with positive orientation - consists of the respondents with manifestations of normal type of perfectionism.
\end{abstract}

Keywords: organizational and professional factors; perfectionism; scientific and pedagogical staff of higher school; teachers; university.

\section{Introduction}

Perfectionism in personality has been receiving attention in psychology for many years. Such interest to this concept can be explain by an increasing speed of life, a social development, a growing competition, a cult of rationality and a pursuit of excellence. These factors demand an aspiration of the personality towards self-improvement, a faultlessness in everything, an achievement of new heights and setting high performance standards. The perfectionism is quite complicated personal trait, which covers all spheres of human life, especially professional activity. 
Grubi, 2020. Organizational and Professional Factors of Perfectionism in Scientific and Pedagogical Staff of Higher School

The interest to the study of perfectionism in scientific and pedagogical staff of high school can be explained by factors such as modernization \& development of higher education, access to the Bologna Process and access to European educational research environment, etc. New requirements \& standards for professional activity arise before lecturers and professors, so these factors demand from scientific and pedagogical staff of high school an achievement of new heights, a desire to be the best, obtaining success by focusing on avoiding failure.

Hence, the goal of article is to investigate the organizational and professional factors of perfectionism, in scientific and pedagogical staff of higher school and to explore factors. This will have a big influence on the formation of positive and negative perfectionism. The analysis of the obtained results will allow us to compile a program to prevent negative form of perfectionism, as well as the development of positive form of perfectionism in scientific and pedagogical staff of higher school in the future.

\section{Literature review}

The analysis of the scientific literature indicates that there are many definitions of perfectionism, but despite multiple studies of this phenomenon, the definition of perfectionism is still open. Based on the analysis of the literature, the definitions of perfectionism should be classified into three approaches.

Perfectionism as a personality trait, which is characterized by striving for setting excessively high standards and requirements for performing duties and activities at a higher level than circumstances require, as well as in the pursuit of the impeccable performance of the task, accompanied by tendencies towards overly critical evaluations of one's behavior (Besharata, et al., 2010).

Perfectionism as a personality disposition, which is characterized by striving for flawlessness and setting exceedingly high standards, then needed, for performance accompanied by tendencies for overly critical evaluations (Flett et al., 2003).

Perfectionism as a tool of self-development, as inner knowing that there is more to life than the mundane, and a desire to create meaning of one's life by doing the best one is capable of doing (Silverman, 2010).

An analysis of the scientific literature shows that the perfectionism has an impact on school settings (Damian et al., 2016; Rice et al., 2016; Stoeber, 2008) and it is emphasized that it has advantages in academic achievements, but disadvantages too. Teachers-perfectionists who combine high performance with flexible standards have more effective study habits and their self-determination is higher (Rice et al., 2016). At the same time, teachers-perfectionists with inflexible standards, striving for high performance, get decreased achievement motivation and decreased academic self-confidence (Rice et al., 2016). This decreasing 
achievement motivation can be explained that teachers interpret their high achievement negatively (Damian et al., 2016). They evaluate their work with alltime increasing standards, but at the same time, their achievements stay at the same level, so it is leading to decreased achievement motivation.

\section{Methodology}

The research of the organizational and professional factors of perfectionism in scientific and pedagogical staff of higher school was conducted during 20162019 within the pedagogy field. 1068 teachers of higher school from different cities and regions of Ukraine took part in our study.

In our investigation, ten different variables of scientific and pedagogical staff of higher school were studied. For convenience, these variables were conventionally divided into two groups: socio-demographic characteristics (an age, a gender, a place of residence) and organizational and professional characteristics (an job experience, an academic degree, a post, a direction of teaching activity, a number of students, a level of famousness of higher school, a level of social-psychological climate).

The findings of the social-demographic variables in terms of age indicate that $24,1 \%$ of respondents are up to 35 years old, $25,6 \%$ of them are $35-45$ years old, $27,1 \%$ of them are $45-55$ years old, and finally $23,2 \%$ of them are more than 55 years old. The findings of the social-demographic variables of sample members indicate that $69,8 \%$ of sample members were female and $30,2 \%$ were male; $18,2 \%$ of respondents are living in the center of Ukraine and $81,8 \%$ are living in different regions of Ukraine.

The findings of organizational and professional variables in terms of job experience indicate that $23.5 \%$ of respondents have less than 5 years job experience, $27.8 \%$ of them have $5-15$ years job experience, $24.0 \%$ have $15-25$ years job experience, and $24.6 \%$ of them have job experience more than 25 years. According to the academic degree, the findings of the organizational and professional variables of sample members indicate that $50.6 \%$ of sample members were without academic degree, $45.5 \%$ were $\mathrm{PhDs}$ and $3.9 \%$ were Doctors of Science.

The Law on Education (Adopted by the Verkhovna Rada on 5 September 2017) in the chapter "On the Approval of the Qualification Characteristics of the Professions (Positions) of Pedagogical and Scientific and Pedagogical Workers of Educational Establishments" specifies the qualification requirements. According to the Order such posts as an assistant department (Code КП - 2310.2) and a senior lecturer (Code КП - 2310.2) have a higher education at specialist's or/and master's degree level (The Law on Education). 
Grubi, 2020. Organizational and Professional Factors of Perfectionism in Scientific and Pedagogical Staff of Higher School

According to the post, the findings of sample members indicate that $27.1 \%$ of sample members were Assistants department (in Ukraine it is the lowest post of scientific and pedagogical staff of higher school), 32.5\% were senior lecturers, $34.2 \%$ were associate professors of the department and only $6.2 \%$ were professors of the department.

According to the direction of teaching activity, all respondents were divided into 2 groups: social and humanities - 35.7\% and natural sciences and mathematics - $64.3 \%$. The findings of the organizational and professional variables of sample members indicate that $21.8 \%$ of sample work directly with less than 20 students, $26.3 \%$ work directly with 20-50 students and $51.9 \%$ members work with more than 50 students. According to the level of famousness of higher school, the sample members indicate that $6.3 \%$ of respondents work at university with low level of famousness, 56.7\% with average level of famousness and $36.9 \%$ with high level of famousness of higher school. According to the results of the cluster analysis, the correlation of indicators was identified and groups of teachers, depending on the level of social-psychological climate $(18.5 \%$ - low, 42.4 - medium, 39.1 - high) were selected. The findings are indicated in table 1.

In our study, we used "Differential Test of Perfectionism" (Zolotareva, 2013) for determination the perfectionism in scientific and pedagogical staff of higher school. This test consists of 24 statements, which are equally distributed on two scales "normal perfectionism" and "pathological perfectionism".

"Normal perfectionism" implies a harmonious desire of the person to perfection, which does not conflict with other motives and is based on such parameters as: an ability to get pleasure, an ability to increase self-esteem based on achievements, a hope of success, a capability of light excitement, an easy entry into the activity, a focus on own resources.

Table 1 Organizational and professional characteristics of sample members

\begin{tabular}{|c|c|c|}
\hline $\begin{array}{c}\text { Organizational and } \\
\text { professional characteristics }\end{array}$ & Groups & $\begin{array}{c}\text { Frequency } \\
\text { in \% }\end{array}$ \\
\hline \multirow{4}{*}{ Job experience } & Up to 5 years & 23.5 \\
\cline { 2 - 3 } & 5-15 years & 27.8 \\
\cline { 2 - 3 } & 15-25 years & 24.0 \\
\cline { 2 - 3 } Academic degree & Over 25 years & 24.6 \\
\cline { 2 - 3 } & Without academic degree & 50.6 \\
\cline { 2 - 3 } & PhD (Candidate of Sciences) & 45.5 \\
\hline \multirow{3}{*}{ Post } & Dr. (Doctor of Science) & 3.9 \\
\cline { 2 - 3 } & Assistant department & 27.1 \\
\cline { 2 - 3 } & Senior lecturer & 32.5 \\
\cline { 2 - 3 } & Associate professor of the \\
department & 34.2 \\
\hline
\end{tabular}


SOCIETY. INTEGRATION. EDUCATION Proceedings of the International Scientific Conference. Volume VII, May $22^{\text {th }}-23^{\text {th }}$, 2020. 51-61

\begin{tabular}{|l|c|c|}
\hline & Professor of the department & 6.2 \\
\hline \multirow{2}{*}{ Direction of teaching activity } & Social and humanities & 35.7 \\
\cline { 2 - 3 } & Natural sciences and mathematics & 64.3 \\
\hline \multirow{2}{*}{$\begin{array}{l}\text { Number of students, the } \\
\text { teacher directly works with }\end{array}$} & Up to 20 students & 21.8 \\
\cline { 2 - 3 } & $20-50$ students & 26.3 \\
\hline \multirow{2}{*}{$\begin{array}{l}\text { Level of famousness of higher } \\
\text { school }\end{array}$} & Over 50 students & 51.9 \\
\cline { 2 - 3 } & Low & 6.3 \\
\cline { 2 - 3 } $\begin{array}{l}\text { Level of social-psychological } \\
\text { climate }\end{array}$ & Average & 56.7 \\
\cline { 2 - 3 } & High & 36.9 \\
\cline { 2 - 3 } & Low & 18.5 \\
\hline
\end{tabular}

"Pathological perfectionism" implies the desire of a person for an ideal, perfect result. It is based on the following parameters: inadequately overestimated assessment of one's capabilities, constant dissatisfaction of one's life, disappointment in one's life and oneself, complete rejection of achieving the intended ideal goal, inadequate testing of reality and oneself, feeling of fatigue.

The research data was processed using a parametric and non-parametric package of SPSS 21.0 and Microsoft Excel software.

\section{Research results and discussion}

Using "Differential Test of Perfectionism" (Zolotareva, 2013) we divided respondents into 4 groups according to the levels and forms of perfectionism's manifestation.

The first group, "Absence of perfectionism", consists of the respondents in which the normal and pathological perfectionism are represented at a low level.

The second group respondents with manifestations of pathological type of perfectionism, and we called it "Perfectionism with negative orientation". "Perfectionism with negative orientation" occurs when there is an incorrect ratio of perfectionistic tendencies and disproportionate development in which neither the result does not seem perfect to accept it. Outcomes of perfectionism with negative orientation can lead to procrastination, avoidance, slow decision making, stress, burnout, inflexibility, etc. Negative perfectionist is characterized by an irrational mindset, a penchant for self-criticism, a self-blame and accusation of others, reduced ability to search for help, and by the presence of interpersonal problems, maladaptive coping strategies, emotional inadaptation, etc. In addition, complete rejection from achieving the intended ideal goal, as well as inadequate testing of reality and yourself, chronic feeling of fatigue is possible.

The third group included the respondents in which the pathological and normal types of perfectionism are equally highly represented and conditionally 
Grubi, 2020. Organizational and Professional Factors of Perfectionism in Scientific and Pedagogical Staff of Higher School

we have called this group “Ambivalent perfectionism”. An ambivalent perfectionist can be defined as person who is driven by fear of failure to strive compulsively toward goals beyond reach and reason but at the same time has an ability to increase self-esteem based on achievements, focus on own resources.

The fourth group respondents with manifestations of normal type of perfectionism, and we called it "Perfectionism with positive orientation". "Perfectionism with positive orientation" is characterized by a desire for constructive achievements and positive self-esteem. Positive perfectionist gets pleasure from the activity and strives to self-development and to improvement of the results, taking into account his own capabilities and he is capable to accept the boundaries (personal or situational) of his perfection. The findings are indicated in table 2.

The findings of the manifestations of perfectionism in sample members indicate that group 1 (absence of perfectionism) includes $14.2 \%$ of respondents, group 2 (perfectionism with negative orientation) $-17.2 \%$, group 3 (ambivalent perfectionism) $-49.4 \%$, group 4 (perfectionism with positive orientation) $19,1 \%$ of respondents.

\section{Table 2 The distribution of the investigated teachers by manifestations of perfectionism}

\begin{tabular}{|l|c|}
\hline Groups of respondents for manifestations of perfectionism & Frequency in \% \\
\hline Absence of perfectionism & 14.2 \\
\hline Perfectionism with negative orientation & 17.2 \\
\hline Ambivalent perfectionism & 49.4 \\
\hline Perfectionism with positive orientation & 19.1 \\
\hline
\end{tabular}

According to social-demographic characteristics, in our investigation, the manifestations of perfectionism correlates with the age of respondents $(\mathrm{p}=0.1)$. It is revealed that the number of teachers with absence of perfectionism or ambivalent perfectionism is increasing with age, while the number of perfectionists with negative and positive orientation is smaller.

In our investigation, at a statistically significance level $(\mathrm{p}<0.01)$, the relationship between manifestations of perfectionism and the place of respondents' residence was established. It was found that the number of teachers with perfectionism with negative orientation in the regions (17.6\%) is higher than in the center (14.8\%).

On the other hand, the number of teachers with ambivalence perfectionism is higher in the center (53.4\%) than in regions (48.8\%) and the perfectionists with a positive orientation in the center (23.8\%) are higher than in regions (18.3\%). In our opinion, this situation can be explained by the fact that there are more higher education institutions in the center than in different regional and district centers 
of Ukraine. That is why teachers have the choice; in addition, they can combine their teaching activities at the main working-place with similar work in other higher schools. In other words, teachers from center are not so "fixated" at their main work as teachers living in regions where there are fewer high schools and these teachers, having fear to lose their jobs, make more requests to themselves for being retained in their workplaces.

According to the organizational and professional characteristics, statistically significant differences in manifestations of perfectionism with job experience were found $(\mathrm{p}<0.05)$. In our investigation, teachers with perfectionism with positive orientation become less with the increasing of job experience. Teachers, with job experience 5-15 years, are $25.3 \%$, while teachers who worked over 25 years - only $17.0 \%$. Such data can be explained by exhaustion and burnout (Boswell et al., 2004; Stoeber, 2008). On the contrary, the number of teachers with absence of perfectionism is increasing: $9.3 \%$ of teachers with job experience up to 5 years and $14.7 \%$ of teachers, who have worked more than 25 years.

In our investigation, the manifestations of perfectionism correlate with the academic degree $(p=0.1)$. It was found that quantity of Doctor of Science with absence perfectionism (16.2\%) prevalent, comparing to candidates of science (10.4\%). The probable explanation for some Doctor of Science is the fact that, having reached certain scientific achievements, the Doctor of Science are resting on their "laurels", but this fact needs further investigation. On the other hand, perfectionism with a negative orientation prevails among teachers without academic degree (17.4\%) comparing with PhDs (16.4\%) and Doctor of Sciences (10.8\%). Such data can be explained that teachers without an academic degree are not sure of the stability of the workplace and they start to put higher demands for themselves than circumstances require. In the case of perfectionism with a positive orientation, $\mathrm{PhDs}$ (21.9\%) dominate than teachers without academic degree (19.1\%) and Doctor of Sciences (18.9\%).

In our study, at level of tendency $(\mathrm{p}=0.1)$, there is a correlation between manifestations of perfectionism and the post of respondents. It is revealed that perfectionism with a negative orientation prevails among the assistant's department $(17.9 \%)$, senior teachers $(16.8 \%)$ and associate professors of the department (16.0\%), unlike the professors of the department (10.3\%). This may indicate that teachers without an academic degree, who take the post of assistant department and senior lecturer are unsure of the stability of the workplace and make higher requirements than the circumstances require, which in its turn generates perfectionism with negative orientation. In terms of perfectionism with positive orientation, it is dominated at the associate professors of the department (23.6\%), senior lecturer (19.8\%) and professors of the department (19.0\%). Such situation can be explained by the fact that teachers who have worked for quite 
Grubi, 2020. Organizational and Professional Factors of Perfectionism in Scientific and Pedagogical Staff of Higher School

long time in higher school have scientific achievements and are more confident in the stability of the workplace.

At level of tendency ( $\mathrm{p}=0.1$ ) there is a correlation between the manifestations of perfectionism and direction of teaching activity. It has been found out that quantity of natural sciences and mathematic teachers with positive orientation (21.8\%) is bigger than social and humanities teachers (16.7\%), but a perfectionism with negative orientation also dominates (17.5\% - natural sciences and mathematics and $15.8 \%$ - social and humanities). On the other hand, absence of perfectionism at social and humanities teachers prevails (14.5\% - social and humanities, $17.5 \%$ - natural sciences and mathematics) and ambivalent perfectionism prevails too $(53.0 \%$ - social and humanities, $49.4 \%$ - natural sciences and mathematics). In our opinion, the obtained data can be explained by the specifics of the natural sciences and mathematics direction, which requires from teachers to be more accuracy and meticulousness in contrast to the socialhumanitarian direction within which the paradigmatic multiplicity of scientific knowledge is presented.

In our study, statistically significant differences $(\mathrm{p}<0.05)$ in the manifestations of perfectionism were found, depending on number of students, the teacher directly works with. It was found that the number of teachers with absence of perfectionism and teachers with perfectionism with negative orientation is increasing with the growing number of students. Thus, if the number of students with which the teacher communicates varies up to 20 people, the absence of perfectionism is found in $9.3 \%$, while if the number is more than 50 students, the teacher with the absence of perfectionism is found $14.2 \%$. A similar tendency is found for teachers with a negative orientation of perfectionism. The obtained data for perfectionism with negative orientation, in our opinion can be explained by the fact that the teacher, who works with a large student audience, feels more pressure to satisfy all requirements, to keep the audience, to be interesting for students. The opposite situation there is with ambivalent perfectionism, where the number of teachers increases with the decreasing of student audience (up to 20 students - 58.5\%, more than 50 students - $47.4 \%$ ). It is interesting that the number of students, the teacher directly works with is not important to teachers with a positive orientation. Teachers with a positive orientation are looking for communication with students constructively and qualitatively, regardless of their number.

Our investigation also illustrates that the number of teachers with perfectionism with a negative orientation and ambivalence perfectionism depends on the subjective assessment of the famousness's level of higher school where they work. It was found that the number of teachers with perfectionism with negative orientation is higher in the case of low evaluation of the university and is $27.1 \%$ of respondents. However, the number of teachers who rated level of 
famousness of higher school as high is only $12.8 \%(\mathrm{p}<0.01)$. This situation can be explained by the fact that teachers with perfectionism with a negative orientation, who rated the level of famousness of higher school as low, are taken care of this situation, overextending themselves. For teachers with ambivalent perfectionism, the situation is opposite. The number of teachers who evaluate the level of famousness of higher school as low is $33.9 \%$, and high is $52.6 \%(\mathrm{p}<0.01)$.

The results of cluster analysis at level of tendency $(p=0.1)$ revealed that the number of teachers with absence of perfectionism decreases with the increasing of socio-psychological climate at the chair/department $(15.9 \%$ - low level of climate, $9.7 \%$ - high level of climate). The number of teachers with perfectionism with a positive orientation increases with the increasing of socio-psychological climate at the chair/department (18.5\% - low level of climate, $22.5 \%$ - high level of climate).

There is an expected tendency that in the case of a good social-psychological climate, there will be more teachers with perfectionism with a positive orientation and fewer with perfectionism with a negative orientation. But this fact was confirmed only for female teachers, where the highest level of perfectionism with positive orientation is fixed at high level of socio-psychological climate. For male teachers, a paradox picture was revealed. By the results of ANOVA, perfectionism with positive orientation is fixed at the lowest level of sociopsychological climate. Instead, it has been found that the highest level of climate correlates with perfectionism with negative orientation (fig.1).

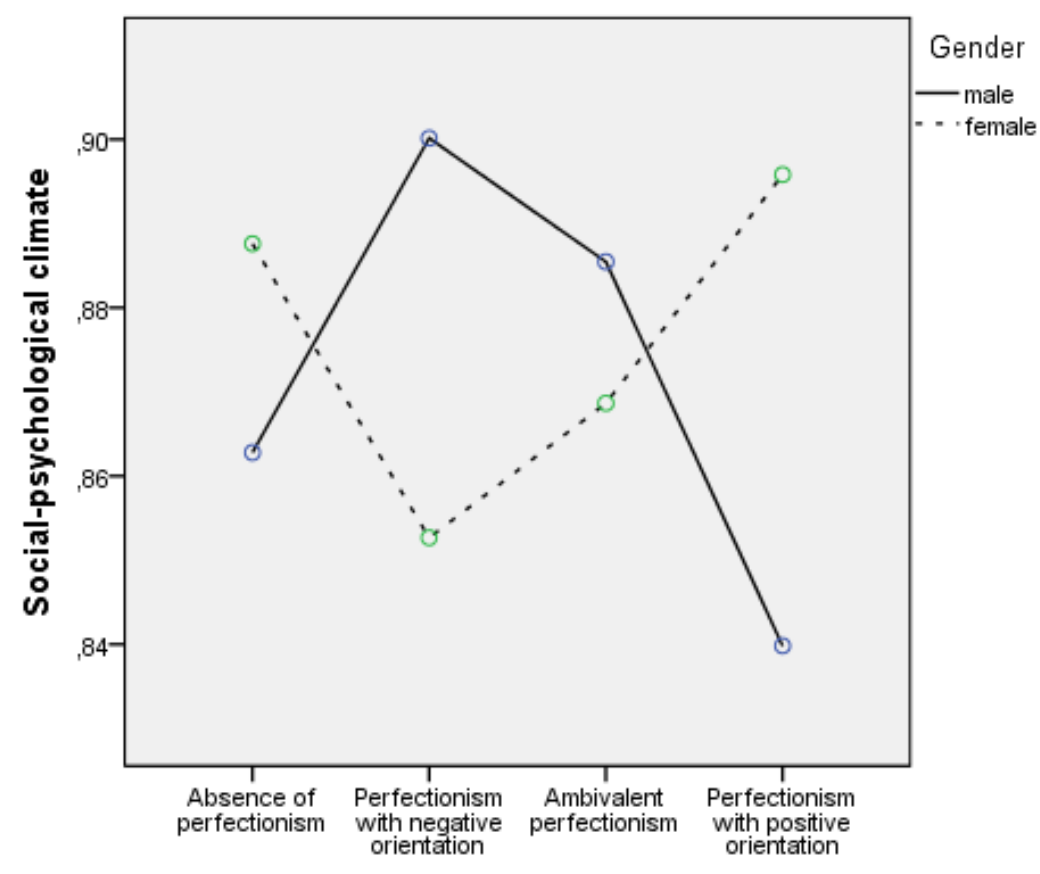

Figure 1 Peculiarities of the manifestation of perfectionism depending on the sociopsychological climate of the organization (based on the results of ANOVA) 
Grubi, 2020. Organizational and Professional Factors of Perfectionism in Scientific and Pedagogical Staff of Higher School

Men are characterized by a "fear of failure" in their professional career, in the desire to be a "real" man, to assert themselves. The "fear of failure" is related to the "fear of success" in non-traditional spheres (such as education), especially for highly masculine men (Harvey et al., 2008; Peters et al., 1980). These findings were also confirmed in our study. In this case, fulfilling the gender role for men, will be difficult in all "non-traditional" spheres, is particularly dangerous in pedagogical activity to its specific goals.

These findings require further research and interpretation, and it is worth recalling the fact of gender inequality inherent in Ukrainian society, where the field of education is more typical for women. Accordingly, men in the non-male professional field are more prone to stress, which may affect the adequacy of perceiving reality.

\section{Conclusions}

The findings of this investigation shows the impact of social-demographic factors on the manifestations of perfectionism: the number of teachers with absence of perfectionism or ambivalent perfectionism is increasing with age; the number of teachers with perfectionism with negative orientation in the regions is higher than in the center, on the other hand the number of teachers with perfectionism with a positive orientation in the center are higher than in regions.

According to organizational and professional factors, in our investigation it was found that teachers with perfectionism with a positive orientation become less with the increasing of their job experience. $\mathrm{PhD}$ teachers with positive orientation perfectionism dominate than teachers without academic degree. It was revealed that perfectionism with negative orientation prevails among the assistants, senior teachers and associate professors, unlike the professors of the department. Quantity of natural sciences and mathematic teachers with positive orientation, as well as perfectionism with negative orientation is bigger than social and humanities teachers. It was found that the number of teachers with absence of perfectionism and teachers with perfectionism with negative orientation is increasing with the growing number of students, at the same time the number of students is of not important to teachers with a positive orientation. Number of teachers with absence of perfectionism decreases with the increasing of sociopsychological climate and number of teachers with perfectionism with positive orientation increases with the increasing of socio-psychological climate at the chair/department.

The prospects for further research will be directed at developing a program for prevention the perfectionism with negative orientation, which are aimed to reduce the level of stress and prophylaxis measures of burnout. 
The findings can be useful for developing and improving teacher's efficacy. The suggestions arising from this study are presented with the hope that other researchers will find them interesting enough to pursue in the future, as a research starts where another has ended and ends where another starts.

\section{References}

Besharat, M.A., Pourhosein, R., Rostami, R., \& Bazzazian, S. (2011). Perfectionism and fatigue in multiple sclerosis. Psychology and Health, 26(4), 419-432.

Boswell, W.R., Olson-Buchanan, J.B., \& Lepine, M.A. (2004). Relations between stress and work outcomes: The role of felt challenge, job control, and psychological strain. Journal of Vocational Behavior, 64, 165-181. DOI:10.1016/S0001-8791(03)00049-6

Damian, L.E., Stoeber, J., Negru-Subtirica, O., \& Băban, A. (2017). On the development of perfectionism: The longitudinal role of academic achievement and academic efficacy. Journal of personality, 85(4), 565-577. DOI:10.1111/jopy.12261

Flett, G.L., Besser, A., Davis, R.A., \& Hewitt, P.L. (2003). Dimensions of Perfectionism, Unconditional Self-Acceptance, and Depression. Journal of Rational-Emotive and Cognitive-Behavior Therapy, 21(2), 119-138. DOI: 10.1023/A:1025051431957

Leonard, N.H., \& Harvey, M. (2008). Negative perfectionism: Examining negative excessive behavior in the workplace. Journal of Applied Social Psychology, 38(3), 585-610. DOI: 10.1111/j.1559- 1816.2007.00318.x

Peters, L.H., O’Connor, E.J., \& Rudolf, C.J. (1980). The behavioral and affective consequences of performance-relevant situational variables. Organizational Behavior and Human Performance, 25, 79-96. DOI:10.1016/0030-5072(80)90026-4.

Rice, K.G., Richardson, C.M., \& Ray, M.E. (2016). Perfectionism in academic settings. In F. M. Sirois \& D. S. Molnar (Eds.), Perfectionism, health, and well-being (pp. 245-264). Cham, Switzerland: Springer International Publishing.

Silverman, L.K. (2010). Perfectionism is not a malady [Data file]. Retrieved from https://www.positivedisintegration.com/Silverman2010.pdf

Stoeber, J., \& Rennert, D. (2008). Perfectionism in school teachers: Relations with stress appraisals, coping styles, and burnout. Anxiety, Stress, \& Coping, 21(1), 37-53. DOI: 10.1080/10615800701742461.

The Law on Education (Adopted by the Verkhovna Rada on 5 September 2017). Retrieved from www.venice.coe.int/webforms/documents/default.aspx?pdffile=CDL-REF (2017)047-e

Zolotareva, A. (2013). Standartizacija metodiki "Differencial'nyj test perfekcionizma". Izvestija Volgogradskogo Gosudarstvennogo Pedagogicheskogo Universiteta, 10(85), 142-146. 